\title{
Optimal Coordinated Design of PSS and UPFC-POD Controller Using Dolphin Echolocation Optimization Algorithm for Damping Oscillation
}

\author{
Ali Nasser Hussain and Shaymaa Hamdan Shri \\ Department of Electrical Power Engineering Techniques, \\ Electrical Engineering Technical College, Middle Technical University, Baghdad, Iraq
}

\begin{abstract}
To enhance the stability of the power system and the system damping is improved, supplementary damping controller is required connected with a power system in the form of PSS and POD. In order to achieve better performance and optimal response of the controller, proposed a technique a new optimization is known Dolphin Echolocation Optimization (DEO) algorithm. Echo is sonar similar used by the dolphin for navigation and hunting. This ability in dolphin made her development of a new optimization method. Therefore, the process for tuning optimal individual and coordinated design of (PSS and UPFC-POD) using (DEO) algorithm gave the best damping resulting compare with (PSO) algorithm.
\end{abstract}

Key words: Low-frequency, oscillation, PSS, UPFC, DEO, POD

\section{INTRODUCTION}

The main objective of the electric power system is generate and transfer the active and reactive power required from the different types of loads linked to the power system. The ability of synchronous generators in the power system to stay synchronism after small disorders defined as small signal stability that is a branch from a phase angle related to instability problem. Its depend on the ability to maintain a balance between the mechanical and electromagnetic power of each synchronous machine connected to the power system. Any change in electromagnetic torque after a disorder can decay into 2 component a synchronizing torque component and a damping torque component. The decrease damping torque cause low-frequency oscillations (Prasertwong et al., 2010).

LFO result in loss of synchronism if damping inadequate from control devices. AVR is helping in regulating voltage and improve system stability but the high performance of AVR a negative effect on the power system as voltage drop, power oscillation and other problems. Therefore, Power System Stabilizer (PSS) installed with AVR, to reduce the effect of AVR and damping low-frequency oscillation. But with increasing demand, loads and long transmission line, make a PSS impractical in the inter-area mode (Usman et al., 2012).
In 1980's entered a new technology to solve problems of power systems defined flexible $\mathrm{AC}$ transmission systems FACTS where played an important role in power system not only in enhances the dynamic performance but also enhances the control power flow increase power transfer capability, damping oscillation and system stability (Mustafa et al., 2013).

The Unified Power Flow Controller (UPFC) is one of the most important of FACTS device. Where it combines the characteristics of 2 other FACTS devices (STATCOM and SSSC). UPFC is able to control all the parameters affecting power flow such as impedance, voltage and phase angle in power system grides (Shegaw and Jyothsna, 2017).

To overall improve system performance must coordination among PSS and UPFC-POD controllers. Uncoordinated between (POD and PSS) caused destabilizing interactions and therefore, unstable be power system. Many research were made in coordinated design between POD and PSS controllers to the tuning of controllers parameters for helpful damping such as adaptive Bacterial-Foraging oriented by Particle Swarm Optimization (BF-PSO) algorithm (Esmaili et al., 2013), differential evolutionary algorithm (Heydari et al., 2014). Genetic Algorithm (GA), Particle Swarm Optimization (PSO) and Gravitational Search Algorithm (GSA) are employed to optimize the coordinated structure parameters (Khadanga and Satapathy, 2015) and Symbiotic Organisms Search (SOS) (Alomoush, 2017).

Corresponding Author: Ali Nasser Hussain, Department of Electrical Power Engineering Techniques, 
This study presents a robust technique to enable enhance the power system dynamic performance know Dolphin Echolocation Optimization (DEO). The DEO algorithm is employed for tuning the parameters of the multiple damping stabilizers in coordination design based on eigenvalue objective function. Simulation results for a (SMIB) equipped with UPFC show the robust of the individual stabilizers and dual coordination between the proposed damping stabilizers comparison with the performance of PSO algorithm.

\section{MATERIALS AND METHODS}

Model of system: In this study use the SMIB power system with UPFC as shown in Fig. 1. The system contains generator is connected with infinite bus via. the transmission line and UPFC.

The UPFC is contains 2 Voltage Sources Converter (VSCs) as shown in Fig. 1. Voltage Source Converters (VSC-1 and VSC-2) are coupled via. the DC voltage link. VSC-1 is connected parallel with the transmission line by Excitation Transformer (ET). VSC-2 is connected series in transmission line via. a Boosting Transformer (BT) (Safari et al., 2015). Structure of UPFC with POD controller shown in Fig. 2 where $\mathrm{M}$ can be $\mathrm{mE}$, $\mathrm{mB}, \delta \mathrm{m}$ and $\delta \mathrm{B}$.

In order to maintain the power flow between the VSC-1 and VSC-2 converters, a DC voltage regulator must insert in the UPFC device. The DC voltage is controlled by modulating the phase angle $(\delta \mathrm{E})$ of the Excitation Transformer (ET) voltage by adding a PI control as shown in Fig. 3 (Sedighizadeh et al., 2013).

Non-linear dynamic model of UPFC: In order to study non-linear dynamic model of the system installed with UPFC using Park's transformation as given in Eq. 1-3 (Hussain et al., 2013a, b):

$$
\begin{aligned}
& {\left[\begin{array}{c}
v_{\text {Etd }} \\
v_{\text {Etq }}
\end{array}\right]=\left[\begin{array}{cc}
0 & -\mathrm{XE} \\
\mathrm{XE} & 0
\end{array}\right]\left[\begin{array}{c}
i_{\mathrm{Ed}} \\
i_{\mathrm{Eq}}
\end{array}\right]+\left[\begin{array}{l}
\frac{\mathrm{mE} \mathrm{V}_{\mathrm{DC}} \cos \delta_{\mathrm{E}}}{2} \\
\frac{\mathrm{mE} \mathrm{V}_{\mathrm{DC}} \sin \delta_{\mathrm{E}}}{2}
\end{array}\right]} \\
& {\left[\begin{array}{c}
v_{\text {Btd }} \\
v_{\text {Btq }}
\end{array}\right]=\left[\begin{array}{cc}
0 & -\mathrm{XB} \\
\mathrm{XB} & 0
\end{array}\right]\left[\begin{array}{c}
\mathrm{i}_{\mathrm{Bd}} \\
\mathrm{i}_{\mathrm{Bq}}
\end{array}\right]+\left[\begin{array}{l}
\frac{\mathrm{mB} \mathrm{V}_{D C} \cos \delta_{\mathrm{B}}}{2} \\
\frac{\mathrm{mB} \mathrm{V}_{D C} \sin \delta_{\mathrm{B}}}{2}
\end{array}\right]}
\end{aligned}
$$

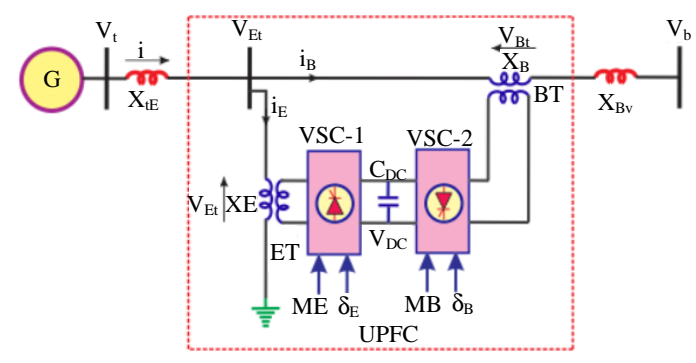

Fig. 1: SMIB power system with UPFC

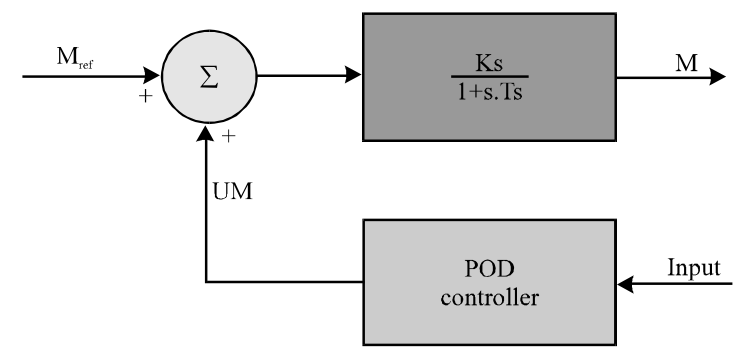

Fig. 2: UPFC with damping controller

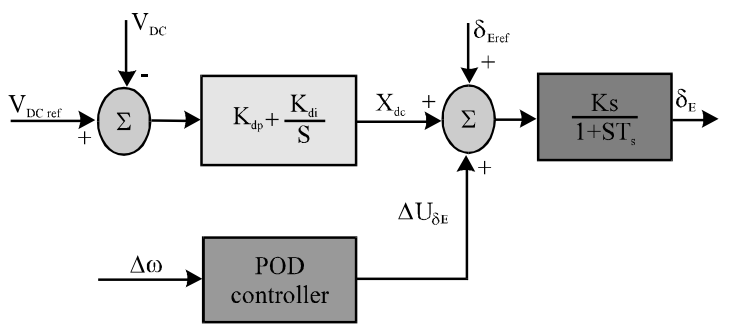

Fig. 3: UFPC with DC voltage regulator and damping controller

$$
\begin{aligned}
& \frac{\mathrm{d} v_{D C}}{\mathrm{dt}}=\frac{3 \mathrm{~m}_{\mathrm{E}}}{4 \mathrm{C}_{\mathrm{DC}}}\left[\begin{array}{ll}
\cos \delta_{\mathrm{E}} & \sin \delta_{\mathrm{E}}
\end{array}\right]\left[\begin{array}{c}
\mathrm{i}_{\mathrm{Ed}} \\
\mathrm{i}_{\mathrm{Eq}}
\end{array}\right]+ \\
& \frac{3 \mathrm{mB}}{4 \mathrm{C}_{\mathrm{DC}}}\left[\begin{array}{ll}
\cos \delta_{\mathrm{B}} & \sin \delta_{\mathrm{B}}
\end{array}\right]\left[\begin{array}{l}
\mathrm{i}_{\mathrm{Bd}} \\
\mathrm{i}_{\mathrm{Bq}}
\end{array}\right]
\end{aligned}
$$

where, $v_{E t}, i_{E}, v_{B t}$ and $i_{B}$ are the excitation voltage, excitation current, boosting voltage and boosting current, respectively in which $\mathrm{d}$ and $\mathrm{q}$ subscripts stand for $\mathrm{dq}$ reference frame; $C_{D C}$ and $V_{D C}$ are the DC link capacitance and voltage, respectively. From Fig. 1, we can find Eq. $4-6$ :

$$
\begin{gathered}
V_{t}=j X_{t E i}+V_{E t} \\
V_{E t}=V_{B t}+j X_{v} i_{B}+V_{b} \\
i=i_{E}+i_{B}
\end{gathered}
$$


where, $I, v_{t}$ and $v_{B}$ are the armature current, generator terminal voltage and infinite bus voltage, respectively; $\mathrm{x}_{\mathrm{E}}$ and $x_{B}$ are the $E_{T}$ and $B_{T}$ reactance's, respectively. The current Eq. 7-9 of excitation and boosting transformers can be written as:

$$
\begin{aligned}
& \mathrm{i}_{\mathrm{Ed}}=\frac{\mathrm{XB} \Sigma}{\mathrm{Xd} \Sigma} \mathrm{E}_{\mathrm{q}}^{\prime}-\frac{\mathrm{mE} \sin \delta_{\mathrm{E}} \mathrm{V}_{\mathrm{DC}} \mathrm{X}_{\mathrm{Bd}}}{2 \mathrm{Xd} \Sigma}+ \\
& \frac{\mathrm{XdE}}{\mathrm{Xd} \Sigma}\left(\mathrm{Vb} \cos \delta+\frac{\mathrm{mB} \sin \delta_{\mathrm{B}} \mathrm{V}_{\mathrm{DC}}}{2}\right) \\
& \mathrm{i}_{\mathrm{Eq}}=\frac{\mathrm{mE} \cos \delta_{\mathrm{E}} \mathrm{V}_{\mathrm{DC}} \mathrm{XBq}}{2 \mathrm{Xq} \Sigma} \\
& \frac{\mathrm{XqE}}{\mathrm{Xq} \Sigma}\left(\mathrm{Vb} \sin \delta+\frac{\mathrm{mB} \cos \delta_{\mathrm{B}} \mathrm{V}_{\mathrm{DC}}}{2}\right) \\
& i_{B d}=-\frac{X d t}{X d \Sigma}\left(V b \cos \delta+\frac{m B \sin \delta_{B} V_{D C}}{2}\right)+ \\
& \frac{\mathrm{XdE}}{\mathrm{Xd} \Sigma} \frac{\mathrm{mE} \sin \delta_{\mathrm{E}} \mathrm{V}_{\mathrm{DC}}}{2}+\frac{\mathrm{XE}}{\mathrm{Xd} \Sigma} \mathrm{E}_{\mathrm{q}}^{\prime} \\
& \mathrm{i}_{\mathrm{Bq}}=-\frac{\mathrm{mE} \cos \delta \mathrm{E} \mathrm{V}_{\mathrm{DC}} \mathrm{XqE}}{2 \mathrm{Xq} \sum}+ \\
& \frac{\mathrm{Xqt}}{\mathrm{Xq} \Sigma}\left(\mathrm{Vb} \sin \delta+\frac{\mathrm{mB} \cos \delta_{\mathrm{B}} \mathrm{V}_{\mathrm{DC}}}{2}\right)
\end{aligned}
$$

Where:

$\mathrm{XB} \Sigma=\mathrm{XB}^{2} \mathrm{XB}_{\mathrm{v}}$

$\mathrm{XBd}=\mathrm{XB} \Sigma+\mathrm{X}^{\prime} \mathrm{d}+\mathrm{XtE}$

$\mathrm{Xd} \Sigma=\left(\mathrm{x}^{\prime} \mathrm{d}+\mathrm{XtE}+\mathrm{XE}\right)(\mathrm{XB} \Sigma)+\mathrm{XE}\left(\mathrm{x}^{\prime} \mathrm{d}+\mathrm{xtE}\right)$

$\mathrm{Xq} \Sigma=(\mathrm{Xq}+\mathrm{XtE}+\mathrm{XE})(\mathrm{XB} \Sigma)+\mathrm{XE}(\mathrm{Xq}+\mathrm{XtE})$

$\mathrm{XBq}=\mathrm{XB} \Sigma+\mathrm{Xq}+\mathrm{XtE}$

$\mathrm{XdE}=\mathrm{X}^{\prime} \mathrm{d}+\mathrm{XtE}$

$\mathrm{XqE}=\mathrm{Xq}+\mathrm{XtE}$

$\mathrm{Xdt}=\mathrm{X}^{\prime} \mathrm{d}+\mathrm{XtE}+\mathrm{XE}$

$\mathrm{Xqt}=\mathrm{Xq}+\mathrm{XtE}+\mathrm{XE}$

Nonlinear model of the power system: Equation 11-14 represents the non-linear model of the SMIB system of Fig. 1:

$$
\begin{gathered}
\dot{\delta}=\omega_{\mathrm{b}}(\omega-1) \\
\dot{\omega}=\frac{1}{\mathrm{M}}\left(\mathrm{P}_{\mathrm{m}}-\mathrm{P}_{\mathrm{e}} \mathrm{D}(\omega-1)\right) \\
\dot{\mathrm{E}}^{\prime} \mathrm{q}=\frac{1}{\mathrm{~T}^{\prime} \mathrm{do}}\left(\mathrm{Efd}-\mathrm{E}^{\prime} \mathrm{q}-\mathrm{id}\left(\mathrm{xd}-\mathrm{x}^{\prime} \mathrm{d}\right)\right) \\
\dot{\mathrm{E} f d}=\frac{1}{\mathrm{Ta}}\left(\mathrm{ka}\left(\mathrm{V}_{\mathrm{ref}}-\mathrm{Vt}+\mathrm{u}_{\mathrm{pss}}\right)-\mathrm{Efd}\right)
\end{gathered}
$$

Where:

Where:

$$
\begin{aligned}
& \mathrm{P}_{\mathrm{e}}=v_{\mathrm{td}} \mathrm{i}_{\mathrm{d}}+v_{\mathrm{tq}} \mathrm{i}_{\mathrm{q}} ; \mathrm{v}_{\mathrm{t}}=v_{\mathrm{td}}+\mathrm{j} v_{\mathrm{tq}} \\
& v_{\mathrm{td}}=\mathrm{x}_{\mathrm{q}} \mathrm{i}_{\mathrm{q}} ; v_{\mathrm{tq}}=\mathrm{E}^{\prime} \mathrm{q}-\mathrm{x}^{\prime} \mathrm{di} \mathrm{i}_{\mathrm{d}} \\
& \mathrm{i}=\mathrm{i}_{\mathrm{d}}+\mathrm{i}_{\mathrm{q}} ; \mathrm{i}_{\mathrm{d}}=\mathrm{i}_{\mathrm{Ed}}+\mathrm{i}_{\mathrm{Bd}} ; \\
& \mathrm{i}_{\mathrm{q}}=\mathrm{i}_{\mathrm{Eq}}+\mathrm{i}_{\mathrm{Bq}}
\end{aligned}
$$

$\mathrm{P}_{\mathrm{m}}$ and $\mathrm{P}_{\mathrm{e}}=$ The input and output power, respectively

$\mathrm{M}$ and $\mathrm{D}=$ The inertia fixed and damping coefficient, respectively

$\omega \mathrm{b} \quad=$ The synchronous speed

$\omega$ and $\delta=$ The rotor angle and speed, respectively

$\mathrm{Eq}, \mathrm{Efd} \quad=$ The generator internal, field and

and $\mathrm{v}$ terminal voltages, respectively

$\mathrm{T}_{\mathrm{do}}=$ The open circuit field time constant

$\mathrm{xd}, \mathrm{xd}=$ The $\mathrm{d}$-axis reactance, $\mathrm{d}$-axis transient

and $\mathrm{xq}$ reactance and $\mathrm{q}$-axis reactance, respectively

$\mathrm{k}_{\mathrm{a}}$ and $\mathrm{T}_{\mathrm{a}}=$ The exciter gain and time constant, respectively

$\mathrm{v}_{\text {ref }} \quad=$ The reference voltage

Linearized model of a power system equipped with UPFC: The linearized model of the power system shown in Fig. 1 explained in Eq. 15-18 (Hussain et al., 2013a, b):

$$
\Delta \dot{\delta}=\omega \mathrm{b} \Delta \omega
$$

$$
\begin{aligned}
& \Delta \dot{\omega}=-\frac{\mathrm{K}_{1}}{\mathrm{M}} \Delta \delta-\frac{\mathrm{D}}{\mathrm{M}} \Delta \omega-\frac{\mathrm{K}_{2}}{\mathrm{M}} \Delta \mathrm{E}^{\prime} \mathrm{q}-\frac{\mathrm{K}_{\mathrm{pd}}}{\mathrm{M}} \Delta \mathrm{V}_{\mathrm{DC}}- \\
& \frac{\mathrm{K}_{\mathrm{pe}}}{\mathrm{M}} \Delta \mathrm{mE}-\frac{\mathrm{K}_{\mathrm{p} \delta \mathrm{e}}}{\mathrm{M}} \Delta \delta \mathrm{E} \frac{\mathrm{K}_{\mathrm{bp}}}{\mathrm{M}} \Delta \mathrm{mB}-\frac{\mathrm{K}_{\mathrm{p} \delta \mathrm{b}}}{\mathrm{M}} \Delta \delta \mathrm{B}
\end{aligned}
$$

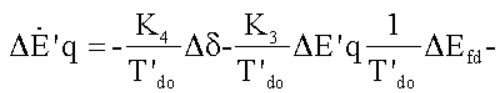

$$
\begin{aligned}
& \frac{\mathrm{K}_{\mathrm{qd}}}{\mathrm{T}_{\mathrm{do}}^{\prime}} \Delta \mathrm{V}_{\mathrm{DC}}-\frac{\mathrm{K}_{\mathrm{qe}}}{\mathrm{T}_{\mathrm{d} 0}^{\prime}} \Delta \mathrm{m}_{\mathrm{E}}-\frac{\mathrm{K}_{\mathrm{q} \delta \mathrm{e}}}{\mathrm{T}_{\mathrm{d} o}^{\prime}} \Delta \delta_{\mathrm{E}}-\frac{\mathrm{K}_{\mathrm{qb}}}{\mathrm{T}_{\mathrm{d} o}^{\prime}} \Delta \mathrm{m}_{\mathrm{B}}- \\
& \frac{\mathrm{K}_{\mathrm{q} \delta \mathrm{b}}}{\mathrm{T}_{\mathrm{do}}^{\prime}} \Delta \delta_{\mathrm{B}} \\
& \Delta \dot{\mathrm{E}}_{\mathrm{fd}}=-\frac{\mathrm{K}_{\mathrm{A}} \mathrm{K}_{5}}{\mathrm{~T}_{\mathrm{A}}} \Delta \delta-\frac{\mathrm{K}_{\mathrm{A}} \mathrm{K}_{6}}{\mathrm{~T}_{\mathrm{A}}} \Delta \mathrm{E}_{\mathrm{q}}^{\prime}-\frac{1}{\mathrm{~T}_{\mathrm{A}}} \Delta \mathrm{E}_{\mathrm{fd}}- \\
& \frac{\mathrm{K}_{\mathrm{A}} \mathrm{K}_{\mathrm{vd}}}{\mathrm{T}_{\mathrm{A}}} \Delta \mathrm{V}_{\mathrm{DC}}-\frac{\mathrm{K}_{\mathrm{A}} \mathrm{K}_{\mathrm{ve}}}{\mathrm{T}_{\mathrm{A}}} \Delta \mathrm{m}_{\mathrm{E}}-\frac{\mathrm{K}_{\mathrm{A}} \mathrm{K}_{\mathrm{v} \delta \mathrm{e}}}{\mathrm{T}_{\mathrm{A}}} \Delta \delta_{\mathrm{E}}- \\
& \frac{\mathrm{K}_{\mathrm{A}} \mathrm{K}_{\mathrm{vb}}}{\mathrm{T}_{\mathrm{A}}} \Delta \mathrm{m}_{\mathrm{B}}-\frac{\mathrm{K}_{\mathrm{A}} \mathrm{K}_{\mathrm{v} \delta b}}{\mathrm{~T}_{\mathrm{A}}} \Delta \delta_{\mathrm{B}}+\frac{\mathrm{K}_{\mathrm{A}}}{\mathrm{T}_{\mathrm{A}}} \mathrm{U}_{\mathrm{pss}}
\end{aligned}
$$

These equations can be arranged in state-space form as:

$$
\Delta \dot{\mathrm{X}}=\mathrm{A} \Delta \mathrm{X}+\mathrm{B} \Delta \mathrm{U}
$$

where, the state vector $\Delta \mathrm{X}$ and control vector $\Delta \mathrm{U}$ are: 


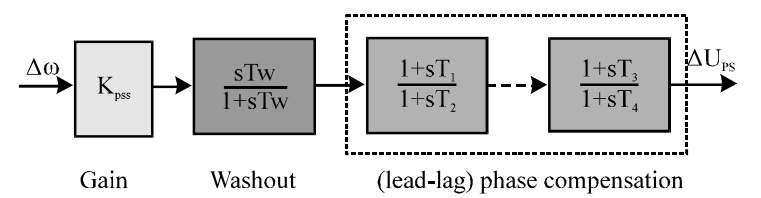

Fig. 4: Structure of the supplementary damping stabilizers

$$
\begin{aligned}
& \Delta \mathrm{X}=\left[\Delta \delta \Delta \omega \Delta \mathrm{E}_{\mathrm{q}}^{\prime} \Delta \mathrm{E}_{\mathrm{fd}} \Delta \mathrm{V}_{\mathrm{dc}}\right]^{\mathrm{T}} \\
& \Delta \mathrm{U}=\left[\Delta \mathrm{U}_{\mathrm{mE}} \Delta \mathrm{U}_{\mathrm{\delta E}} \Delta \mathrm{U}_{\mathrm{mB}} \Delta \mathrm{U}_{\mathrm{\delta b}}\right]^{\mathrm{T}}
\end{aligned}
$$

The structure of the matrices $\mathrm{A}$ and $\mathrm{B}$ is:

$$
\begin{aligned}
& \mathrm{A}=\left[\begin{array}{ccccc}
0 & \omega_{\mathrm{b}} & 0 & 0 & 0 \\
-\frac{\mathrm{K}_{1}}{\mathrm{M}} & -\frac{\mathrm{D}}{\mathrm{M}} & -\frac{\mathrm{K}_{2}}{\mathrm{M}} & 0 & -\frac{\mathrm{K}_{\mathrm{pd}}}{\mathrm{M}} \\
-\frac{\mathrm{K}_{4}}{\mathrm{~T}_{\mathrm{d} 0}^{\prime}} & 0 & -\frac{\mathrm{K}_{3}}{\mathrm{~T}_{\mathrm{d} 0}^{\prime}} & \frac{1}{\mathrm{~T}_{\mathrm{d} 0}^{\prime}} & -\frac{\mathrm{K}_{\mathrm{qd}}}{\mathrm{T}_{\mathrm{d} 0}^{\prime}} \\
-\frac{\mathrm{KAK}_{5}}{\mathrm{TA}} & 0 & \frac{\mathrm{KAK}_{6}}{\mathrm{TA}} & -\frac{1}{\mathrm{TA}} & -\frac{\mathrm{KAK}_{\mathrm{vd}}}{\mathrm{TA}} \\
\mathrm{K}_{7} & 0 & \mathrm{~K}_{8} & 0 & \mathrm{~K}_{9}
\end{array}\right] \\
& B=\left[\begin{array}{cccc}
0 & 0 & 0 & 0 \\
-\frac{\mathrm{K}_{\mathrm{pe}}}{\mathrm{M}} & -\frac{\mathrm{K}_{\mathrm{p} \delta e}}{\mathrm{M}} & -\frac{\mathrm{K}_{\mathrm{pb}}}{\mathrm{M}} & -\frac{\mathrm{K}_{\mathrm{p} \delta b}}{\mathrm{M}} \\
-\frac{\mathrm{K}_{\mathrm{qe}}}{\mathrm{T}_{\mathrm{do}}^{\prime}} & -\frac{\mathrm{K}_{\mathrm{p} \delta e}}{\mathrm{~T}_{\mathrm{do}}^{\prime}} & -\frac{\mathrm{K}_{\mathrm{qb}}}{\mathrm{T}_{\mathrm{do}}^{\prime}} & -\frac{\mathrm{K}_{\mathrm{q} \delta b}}{\mathrm{~T}_{\mathrm{do}}^{\prime}} \\
-\frac{\mathrm{KAK}_{\mathrm{ve}}}{\mathrm{TA}} & -\frac{\mathrm{KAK}_{\mathrm{v} \delta e}}{\mathrm{TA}} & -\frac{\mathrm{KAK}_{\mathrm{vb}}}{\mathrm{TA}} & -\frac{\mathrm{KA} \mathrm{K}_{\mathrm{v} \delta b}}{\mathrm{TA}} \\
\mathrm{K}_{\mathrm{ce}} & \mathrm{K}_{\mathrm{cde}} & \mathrm{K}_{\mathrm{cb}} & \mathrm{K}_{\mathrm{cdb}}
\end{array}\right]
\end{aligned}
$$

Damping controller of UPFC: In order to produce an electrical torque, the damping controller is designed according to a phase compensation method. The 4 control channels in the UPFC $(\mathrm{mE}, \delta \mathrm{E}, \mathrm{mB}$ and $\delta \mathrm{B})$ are being employed in order to produce the damping torque. In this study, $(\delta \mathrm{E})$ is used to damping controller design under various load condition. Figure 4 showing a structure of the supplementary damping stabilizers, the speed deviation $(\Delta \omega)$ is chosen as the input signal to the damping controller. The POD is similar to the PSS in terms of structure and work. Where contains 3 blocks as follows (Ajami and Gholizadeh, 2012).

The gain block determines the amount of damping produced by PSS. The washout block acts as a high-pass filter to prevents the change of steady-state signal and also eliminate the DC offset from the POD or PSS output. The washout time $T \omega$ should have a value in the range of 1-20 sec in this study fixed on $10 \mathrm{sec}$. The phase compensator use to compensates the phase lag caused by the AVR and the field circuit of the generator (Surjan and Garg, 2012).

\section{Design of optimal controllers PSS and UPFC-POD:} The major objective of the coordinated design method is improving the dynamic stability of the power system grids. It can be obtained by a suitable adjustment of the parameters of multiple power system damping controllers between PSS and $\delta \mathrm{E}$ channel of the shunt structure of UPFC-POD device. The POD controller is a lead-lag type. It can be described as Eq. 20:

$$
\mathrm{U}(\mathrm{s})=\mathrm{G}(\mathrm{s}) \mathrm{Y}(\mathrm{s})
$$

where, $\mathrm{G}(\mathrm{s}), \mathrm{Y}(\mathrm{s})$ and $\mathrm{U}(\mathrm{s})$ are the transfer function input signal and output signal of POD controller, respectively. Equation 20 can be expressed in state-space form as Eq. 21:

$$
\Delta \dot{\mathrm{X}} \mathrm{c}=\mathrm{Ac} \Delta \mathrm{Xc}+\mathrm{Bc} \Delta \mathrm{U}
$$

where, $\Delta \mathrm{X}_{\mathrm{C}}$ is the controller state vector. Combining Eq. 19 and 21 for obtaining a closed loop system:

$$
\begin{aligned}
& \Delta \dot{\mathrm{X}}_{\mathrm{cl}}=\mathrm{A}_{\mathrm{cl}} \Delta \mathrm{X}_{\mathrm{cl}} \\
& \Delta \mathrm{X}_{\mathrm{cl}}=\left[\begin{array}{l}
\Delta \mathrm{X} \\
\Delta \mathrm{X}_{\mathrm{c}}
\end{array}\right]
\end{aligned}
$$

The damping ratio $(\zeta)$ of the system is calculated using the software MATLAB given in command:

$$
[\mathrm{Wn}, \text { Zeta, Pole }]=\operatorname{damp}\left(\mathrm{A}_{\mathrm{cl}}\right)
$$

The objective function can be defined as:

$$
\mathrm{J}=\min (\text { Ztta) }
$$

where, $\Delta \mathrm{X}_{\mathrm{c}}, \mathrm{Wn}$, Zeta and Pole are the state vector, natural frequency, damping ratio and poles of the closed-loop system. The target of the optimization process is to maximize $\mathrm{J}$ in order to achieving suitable damping for all modes by moving the dominant poles to the desired location which enhance the system damping characteristics and maximum $\mathrm{J}$ is searched within the limited range of control parameters:

$$
\begin{aligned}
& \mathrm{K}_{\mathrm{f}}^{{ }^{2 i n}} \leq \mathrm{K}_{\mathrm{f}} \leq \mathrm{K}_{\mathrm{f}}{ }^{{ }^{2 a x}} \\
& \mathrm{~T}_{\mathrm{Pr}}{ }^{\text {min }} \leq \mathrm{T}_{\mathrm{Fr}} \leq \mathrm{T}_{\mathrm{Fr}}{ }^{\text {max }} \\
& \mathrm{T}_{\mathrm{Pn}_{\mathrm{n}}{ }^{\text {min }}} \leq \mathrm{T}_{\mathrm{Pn}} \leq \mathrm{T}_{\mathrm{Pn}}
\end{aligned}
$$




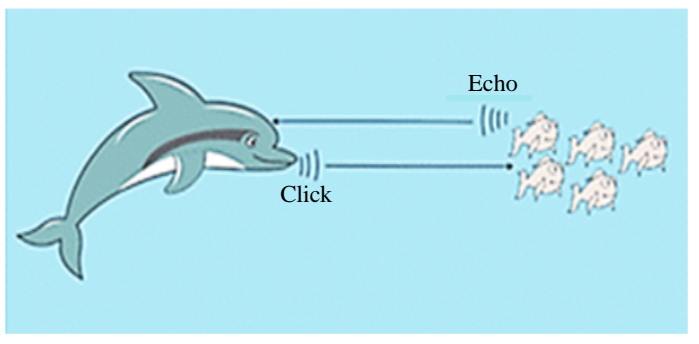

Fig. 5: Real dolphins catching its prey

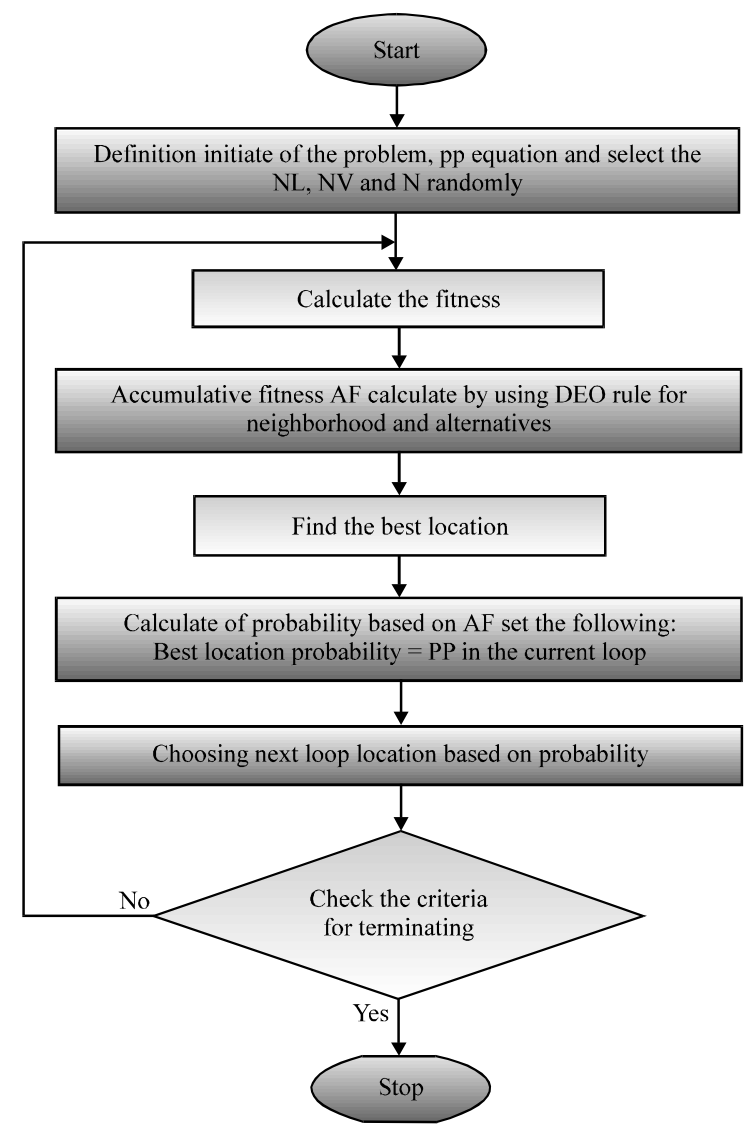

Fig. 6: Flowchart of the DEO algorithm

where, $\mathrm{f}=\mathrm{PSS}, \boldsymbol{\delta}_{\mathrm{E}}, \mathrm{r}=1,3$ and $\mathrm{n}=2,4$. Typical ranges of $\mathrm{K}_{\mathrm{f}}$ is $(0.01-100), \mathrm{T}_{\mathrm{Fr}}$ is $(0.001-1)$ and $\mathrm{T}_{\mathrm{Fn}}$ is $(0.001-0.1)$. $\mathrm{T} \omega=$ $10 \mathrm{sec}$.

Dolphin Echolocation Optimization (DEO) algorithm: Kaveh and Farhoudi (2013) have proposed a new optimization method named Dolphin Echolocation Optimization (DEO). Dolphin sends sound like the sonar for setting the target and its location. This fact mimicked, here as the major feature of the new optimization method. Dolphins beginning looking all around the search space to find the prey. At a dolphin approaches the target, restricts seek and increases its clicks in order to focus on the location target as shown in Fig. 5. In this period, a dolphin will determine distance suitable to reach the target. Can be that we abstract this behavior in the 2 stages: in the first stage the algorithm explore all around the seek space for the performance of a global search, therefore, it should seek for unexplored regions. This task is carried out by exploring some random locations in the search space and in the second stage it focusing on survey around better results achieved from the previous stage (Kaveh et al., 2015). The steps for tuning and flowchart of the DEO algorithm are shown as follows (Fig. 6):

\section{Algorithm 1; DEO algorithm: \\ The steps for the tuning algorithm are as follows \\ (Kaveh and Farhoudi, 2016) \\ Step one "Initialization" \\ This step contains of the initialization for the following:}

- NL random number of location and NV number of variable

- $\quad$ Alternative matrix with dimension [MA×NV] where MA is maximum alternative number in the search space

- Maximum number of loops $\mathrm{N}$

Step two "CF predefining and finding"

- $\quad$ Set $\mathrm{PP}_{1}=0.1$ which represent the convergence factor of the randomly selected location in the first loop

- $\quad$ Find the predefined probability PP by use CF according to the equation following:

$$
\mathrm{PP}\left(\mathrm{Loop}_{\mathrm{i}}\right)=\mathrm{PP}_{1}+\left(1-\mathrm{PP}_{1}\right)\left(\frac{\text { Loop }_{\mathrm{i}}-1}{\text { Loops number-1 }}\right)
$$

Step three "Fitness calculation"

In this study suggested controller design is:

Objective function: $\mathrm{J}=\min$ (zeta)

Fitness function: Max (J)

Step four "Accumulated Fitness AF computation"

Calculate the AF for each jth variable in $\mathrm{L}$ (I, j) location via. using the equation given below:

$\mathrm{k}=-\operatorname{Re}$ to $\operatorname{Re}$

$$
A F_{(A+k) j}=(1 / R e)\left(\text { Re-k)Fitness }{ }_{i}+A F_{(A+k) j}\right.
$$

where, $A F_{(A+k) j}$ is the accumulative fitness of the $(A+k)$ is the alternative to be chosen for the jth

variable, Re is the effective radius in which accumulative fitness of the alternative A's neighbors are affected from its fitness (Re is a quarter search spaces). Fitness (i) is the fitness of location $i$ 
Step five "Best location finding"

- Find the alternative designation to the variable of best location

- Let the $\mathrm{AF}$ for best location alternative = zero

Step six "probability determination and allocation"

- Computation the probability as following Eq. 25:

$$
P(i, j)=\frac{A F_{i j}}{\sum_{i=1}^{L A_{j}} A F_{i j}}
$$

- Assign probability equals to PP for all variables of the best location

$P(i, j)=P P$ and

$P(i, j)=\left(1-P P_{\text {loopi }}\right) P(i, j)$

Step seven "Next loop location selection"

Update of the location value with respect to the allocated probability of its alternative

Step eight "Repetition"

Repeat the steps two to seven even the maximum number of iterations is satisfied

\section{RESULTS AND DISCUSSION}

The dynamic behavior of the system is recognized through the eigenvalues analysis of the system without control under the different loading condition. By solving the system characteristic equation (eig(A)) using MATLAB, the eigenvalues of the open system are computed as shown in Table 1. It is clear from eigenvalues of an open system it is unstable and needs the supplementary stabilizer for stability.

Figure 7-9 shown speed deviation responses of the system without control. Can understand this system is unstable because of positive eigenvalues. Therefore, the oscillations continue increasing under all different loading condition.

Figure 10-12 shown the speed deviation responses of the system with individual controller PSS under nominal, light and heavy loads condition, respectevily. It can be seen that the system oscillations are acceptable damped by applying PSS.

Figure 13-15 shown the speed deviation responses of a system equipped with individual controller UPFC-POD under nominal, light and heavy loads condition, respectevily. It can be seen that the performance of the UPFC-POD is good in damping the system oscillations at all load conditions.

Figure 16-18 show the speed deviation responses of the system with dual-coordinated design
Table 1: Eigenvalues $(\lambda)$ without controller

\begin{tabular}{llll}
\hline$\lambda$ & $\mathrm{NL}$ & $\mathrm{LL}$ & $\mathrm{HL}$ \\
\hline$\lambda_{1}$ & $-18.2682+0.0000_{\mathrm{i}}$ & $-18.1330+0.0000_{\mathrm{i}}$ & $-18.3541+0.0000_{\mathrm{i}}$ \\
$\lambda_{2}$ & $-19.9925+0.0000_{\mathrm{i}}$ & $-19.9918+0.0000_{\mathrm{i}}$ & $-19.9930+0.0000_{\mathrm{i}}$ \\
$\lambda_{3}$ & $0.2837+2.6217_{\mathrm{i}}$ & $0.0581+2.7269_{\mathrm{i}}$ & $0.3283+2.3569_{\mathrm{i}}$ \\
$\lambda_{4}$ & $0.2837-2.6217_{\mathrm{i}}$ & $0.0581-2.7269_{\mathrm{i}}$ & $0.3283-2.3569_{\mathrm{i}}$ \\
$\lambda_{5}$ & $-2.4431+0.0000_{\mathrm{i}}$ & $-2.1689+0.0000_{\mathrm{i}}$ & $-2.5062+0.0000_{\mathrm{i}}$ \\
$\lambda_{6}$ & $-0.0790+0.0000_{\mathrm{i}}$ & $-0.0444+0.0074_{\mathrm{i}}$ & $-0.0347+0.0660_{\mathrm{i}}$ \\
$\lambda_{7}$ & $-0.0506+0.0000_{\mathrm{i}}$ & $-0.0444-0.0074_{\mathrm{i}}$ & $-0.0347-0.0660_{\mathrm{i}}$ \\
$\lambda_{8}$ & $-20.0000+0.0000_{\mathrm{i}}$ & $-20.0000+0.0000_{\mathrm{i}}$ & $-20.0000+0.0000_{\mathrm{i}}$ \\
$\lambda_{9}$ & $-20.0000+0.0000_{\mathrm{i}}$ & $-20.0000+0.0000_{\mathrm{i}}$ & $-20.0000+0.0000_{\mathrm{i}}$ \\
$\lambda_{10}$ & $-20.0000+0.0000_{\mathrm{i}}$ & $-20.0000+0.0000_{\mathrm{i}}$ & $-20.0000+0.0000_{\mathrm{i}}$ \\
\hline
\end{tabular}

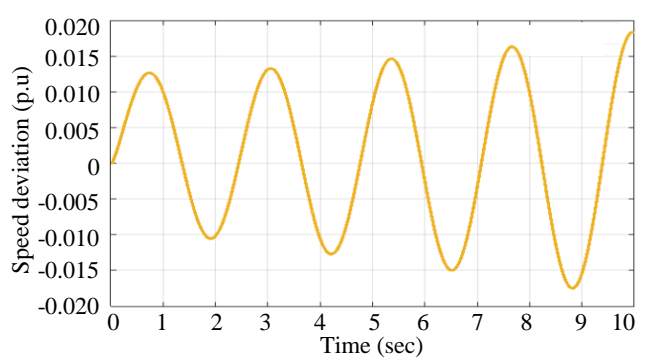

Fig. 7: Speed deviation without control at (NL)

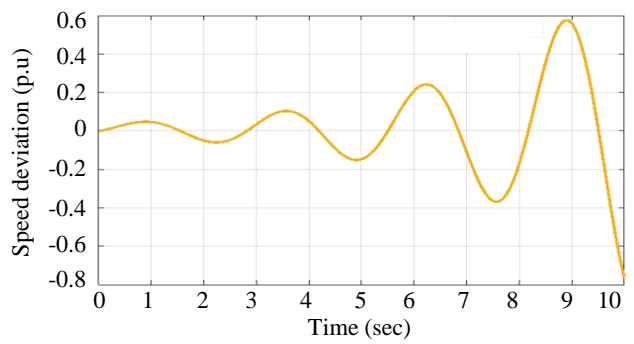

Fig. 8: Speed deviation without control at (LL)

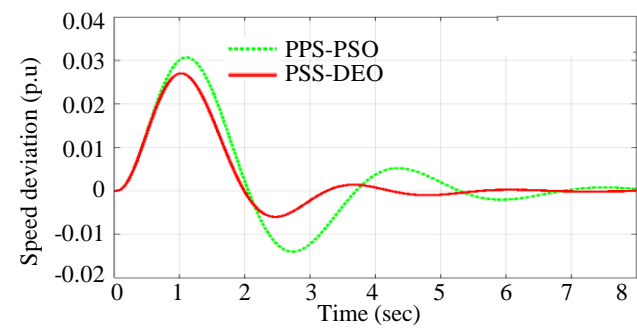

Fig. 9: Speed deviation without control at (HL)

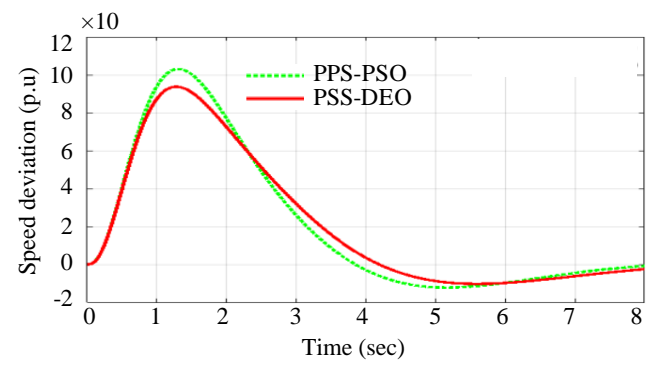

Fig. 10: Speed deviation with PSS at (NL) 


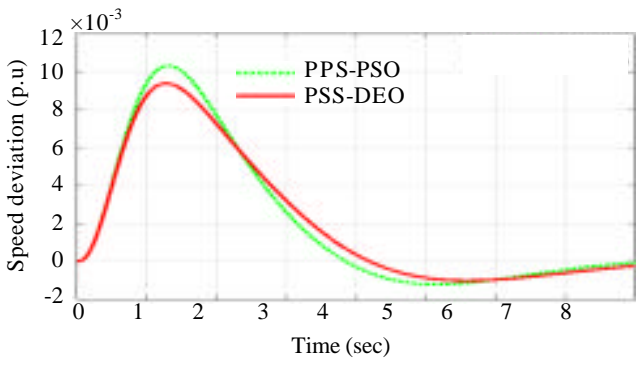

Fig. 11: Speed deviation with PSS at (LL)

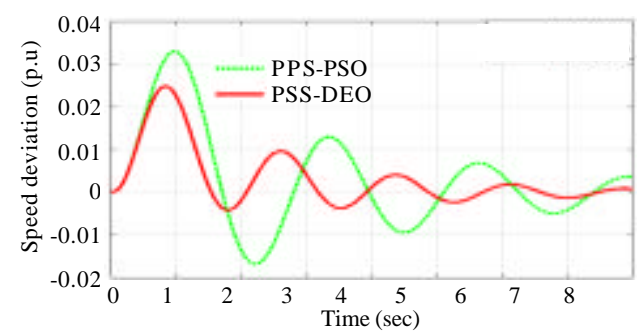

Fig. 12: Speed deviation with PSS at (HL)

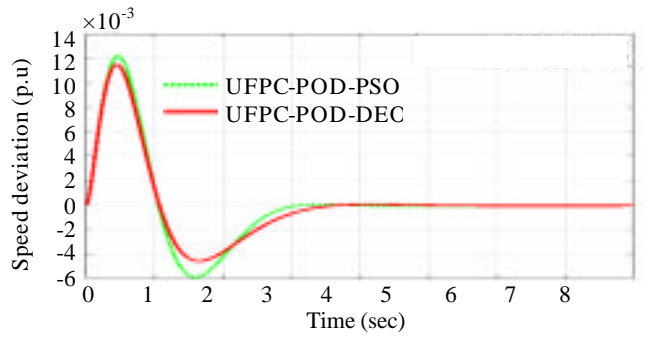

Fig. 13: Speed deviation with UPFC-POD at (NL)

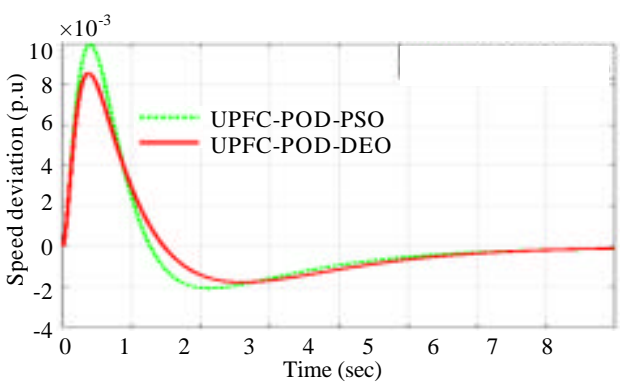

Fig. 14: Speed deviation with UPFC-POD at (LL)

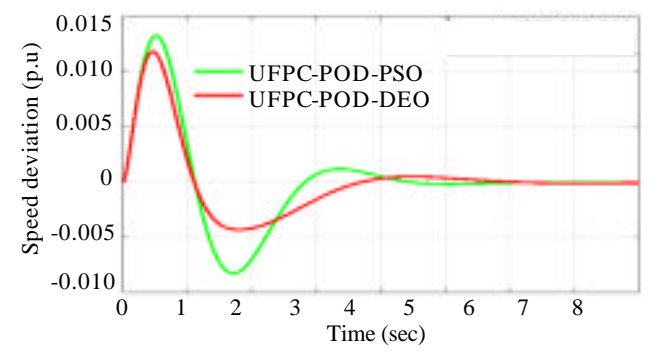

Fig. 15: Speed deviation with UPFC-PODat (HL)

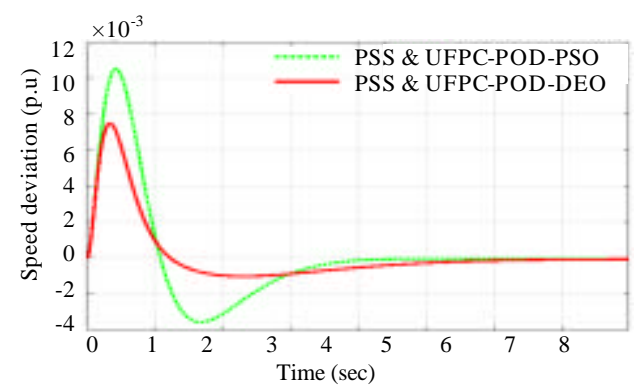

Fig. 16: Speed deviation with PSS \& UPFC-POD at (NL)

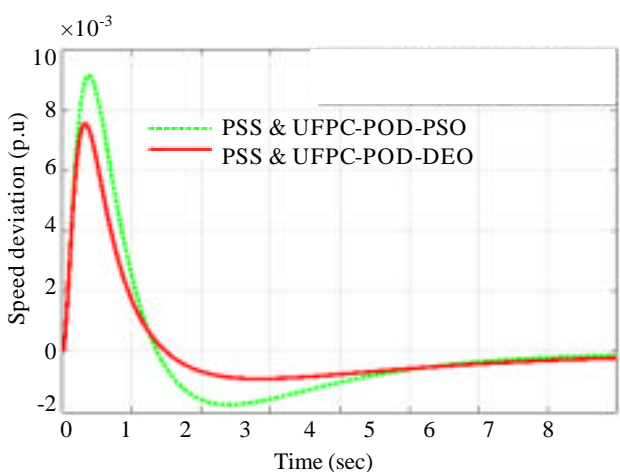

Fig. 17: Speed deviation with PSS \& UPFC-POD at (LL)

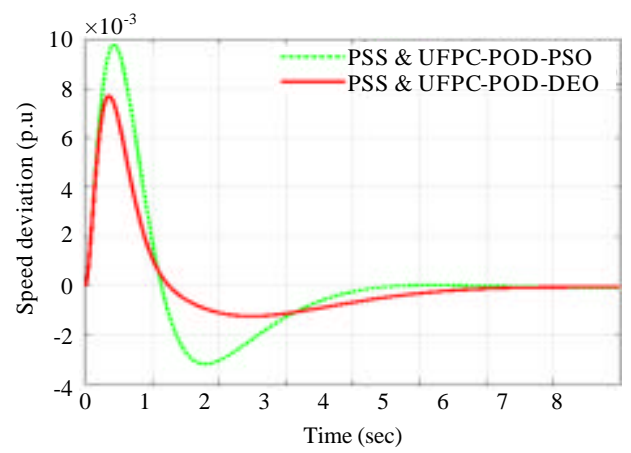

Fig. 18: Speed deviation with PSS \& UPFC-POD at (LL)

between PSS and UPFC-POD under nominal, light and heavy loads condition, respectevily. It can be seen from the figures that better dynamic response is obtained by coordinated design at different load conditions.

Finally, the results confirmed that the system performances resulting from using $\mathrm{DEO}$ algorithm are most effective which have less number of oscillations, less settling time, much faster and less overshoot compared with results PSO algorihm for individual controllers and coordinated design at different loading conditions. The values final of the optimal parameter adjusted by the DEO compared with PSO are shown in Table 2-7 under all different load conditions. 
Table 2: The optimal parameter settings of the PSO \& DEO controller with NL

\begin{tabular}{|c|c|c|c|c|c|c|}
\hline Controller types & Zeta $(\zeta)$ & $\mathrm{K}$ & $\mathrm{T}_{1}$ & $\mathrm{~T}_{2}$ & $\mathrm{~T}_{3}$ & $\mathrm{~T}_{4}$ \\
\hline \multicolumn{7}{|l|}{ PSS } \\
\hline PSO & 0.2875553 & 6.8466 & 0.0025 & 0.0021 & 0.2737 & 0.0012 \\
\hline DEO & 0.3057540 & 16.0422 & 0.5644 & 0.0004 & 0.9807 & 0.0108 \\
\hline \multicolumn{7}{|l|}{ 8E-POD } \\
\hline PSO & 0.7456309 & 38.0621 & 0.0394 & 0.0478 & 0.0348 & 0.0900 \\
\hline DEO & 0.7534196 & 45.0788 & 0.2455 & 0.0874 & 0.6310 & 0.0292 \\
\hline \multicolumn{7}{|l|}{ PSS $^{*}$ and } \\
\hline \multicolumn{7}{|l|}{ 8E-POD** } \\
\hline \multirow[t]{2}{*}{ PSO } & 0.8561725 & $4.5758^{*}$ & $0.3654^{*}$ & $0.0769^{*}$ & $0.5429^{*}$ & $0.0894^{*}$ \\
\hline & & $51.4683^{* *}$ & $0.8695^{* *}$ & $0.0538^{* *}$ & $0.7724^{* *}$ & $0.0256^{* *}$ \\
\hline \multirow[t]{2}{*}{ DEO } & 0.8796861 & $25.6561^{*}$ & $0.9576^{*}$ & $0.0583^{*}$ & $0.0462^{*}$ & $0.0015^{*}$ \\
\hline & & $90.0020^{* *}$ & $0.5917^{* *}$ & $0.0128^{* *}$ & $0.8723^{* *}$ & $0.0106^{* *}$ \\
\hline
\end{tabular}

Table 3: The optimal parameter settings of the PSO \& DEO Controller with LL

\begin{tabular}{|c|c|c|c|c|c|c|}
\hline Controller types & Zeta $(C)$ & $\mathrm{K}$ & $\mathrm{T}_{1}$ & $\mathrm{~T}_{2}$ & $\mathrm{~T}_{3}$ & $\mathrm{~T}_{4}$ \\
\hline \multicolumn{7}{|l|}{$\overline{\text { PSS }}$} \\
\hline PSO & 0.5843249 & 33.0334 & 0.0689 & 0.0990 & 0.0039 & 0.0983 \\
\hline DEO & 0.5908369 & 39.3488 & 0.7382 & 0.0010 & 0.5690 & 0.0004 \\
\hline \multicolumn{7}{|l|}{ 8E-POD } \\
\hline PSO & 0.9828050 & 46.3247 & 0.0069 & 0.0202 & 0.7214 & 0.0254 \\
\hline DEO & 0.9979910 & 63.2032 & 0.7419 & 0.0002 & 0.8229 & 0.0093 \\
\hline \multicolumn{7}{|l|}{$\begin{array}{l}\text { PSS }{ }^{*} \text { and } \\
\text { 8E-POD }\end{array}$} \\
\hline PSO & 0.9913461 & $4.1452^{*}$ & $0.1441^{*}$ & $0.0243^{*}$ & $0.1776^{*}$ & $0.0767^{*}$ \\
\hline DEO & 1.0000000 & $\begin{array}{l}56.7645^{* *} \\
54.0724^{*} \\
83.6855^{* *}\end{array}$ & $\begin{array}{l}0.3795^{* *} \\
0.0863^{*} \\
0.5143^{* *}\end{array}$ & $\begin{array}{l}0.0010^{* *} \\
0.0412^{*} \\
0.0061^{* *}\end{array}$ & $\begin{array}{l}0.0010^{* *} \\
0.1736^{*} \\
0.2153^{* *}\end{array}$ & $\begin{array}{l}0.0303^{* *} \\
0.0448^{*} \\
0.0119^{* *}\end{array}$ \\
\hline
\end{tabular}

Table 4: The optimal parameter settings of the PSO \& DEO controller with HL

\begin{tabular}{|c|c|c|c|c|c|c|}
\hline Controller types & Zeat $(C)$ & $\mathrm{K}$ & $\mathrm{T}_{1}$ & $\mathrm{~T}_{2}$ & $\mathrm{~T}_{3}$ & $\mathrm{~T}_{4}$ \\
\hline \multicolumn{7}{|l|}{ PSS } \\
\hline PSO & 0.1014444 & 17.0048 & 0.9410 & 0.0042 & 1.0000 & 0.0038 \\
\hline DEO & 0.1157705 & 38.7662 & 0.8967 & 0.0038 & 0.6397 & 0.0007 \\
\hline \multicolumn{7}{|l|}{ 8E-POD } \\
\hline PSO & 0.5950562 & 40.9445 & 0.6624 & 0.0834 & 0.1572 & 0.0836 \\
\hline DEO & 0.6177837 & 59.3539 & 0.0583 & 0.0795 & 0.9367 & 0.0621 \\
\hline \multicolumn{7}{|l|}{$\begin{array}{l}\text { PSS* and } \\
\text { 8E-POD** }\end{array}$} \\
\hline \multirow[t]{2}{*}{ PSO } & 0.7210594 & $10.5339^{*}$ & $0.6741^{*}$ & $0.0059^{*}$ & 0.7271 * & $0.0837^{*}$ \\
\hline & & $62.2239^{* * *}$ & $0.8538^{* * *}$ & $0.0333^{* * *}$ & $0.3543^{* * *}$ & $0.0131^{\text {**t }}$ \\
\hline DEO & 0.7546947 & $23.4603^{*}$ & $0.3029^{*}$ & $0.0003^{*}$ & $0.7814^{*}$ & $0.0745^{*}$ \\
\hline & & $94.7977^{\text {*** }}$ & $0.6218^{* * *}$ & $0.0028^{* * * *}$ & $0.3487^{\text {**** }}$ & $0.0277^{* * t}$ \\
\hline
\end{tabular}

$*, * *$ are significant values

Table 5: Loading conditions of system

\begin{tabular}{lll}
\hline Loading conditions & $\mathrm{P}$ (p.u.) & $\mathrm{Q}$ (p.u.) \\
\hline Nominal Load (NL) & 0.8 & 0.114 \\
Light Load (LL) & 0.2 & 0.01 \\
Heavy Load (HL) & 1.2 & $0.4 \mathrm{~A}$ \\
\hline
\end{tabular}

Table 6: Parameters of power system

\begin{tabular}{ll}
\hline Parameters & Power system \\
\hline Generator & $\mathrm{M}=8, \mathrm{D}=0, \mathrm{Xd}=1, \mathrm{X}^{\prime} \mathrm{d}=0.3 \mathrm{Xq}=0.6, \mathrm{~T}_{\mathrm{do}}$ \\
& $=5.044$ \\
Excitation & $\mathrm{K}_{\mathrm{A}}=10, \mathrm{~T}_{\mathrm{A}}=0.05 \mathrm{~s}$ \\
Transmission line & $\mathrm{XtE}=0.1, \mathrm{XBV}=0.6$ \\
Operating condition & $\mathrm{Pe}=0.8, \mathrm{~V}_{\mathrm{t}}=1, \mathrm{~V}_{\mathrm{b}}=1$ \\
UPFC transformers & $\mathrm{XE}=0.1, \mathrm{XB}=0.1$ \\
DC link parameter & $\mathrm{V}_{\mathrm{DC}}=2, \mathrm{C}_{\mathrm{DC}}=1$ \\
UPFC & $\mathrm{m}_{\mathrm{E}}=0.4013, \delta_{\mathrm{E}}=-85.3478^{0} \delta_{\mathrm{B}}=0.0789, \delta_{\mathrm{B}}=-$ \\
& $78.217^{0} \mathrm{Ks}=1, \mathrm{Ts}=0.05 \mathrm{~s}$ \\
\hline
\end{tabular}

Table 7: Parameters of PSO \& DEO

\begin{tabular}{ll}
\hline PSO & DEO \\
\hline N (No. of birds) (30) & NL (No. of Location) (30) \\
Iteration (bird_setp) (50) & Iteration (loopno) (50) \\
C1, C2 (2) & Nalt. (90) \\
w (0.3) & \\
\hline
\end{tabular}

\section{CONCLUSION}

This study is presented the optimal coordinated design of the PSS and UPFC-POD in a SMIB system based on the dolphin echolocation optimization which is capable of attaining the best controller parameters near the optimal global solution under different load conditions. To investigate the effectiveness of the DEO algorithm to adjust the parameters of the proposed control schemes individual (PSS then UPFC-POD) and the simultaneous coordinated design (PSS and UPFC -POD), the results were compared with the results that obtained using the PSO algorithm. Simulation results have shown that the optimal coordinated design of the PSS and UPFC-POD obtained using the DEO has improved the stability and damping of the system and provides better results compared to PSO algorithm. Also by using the optimal coordinated DEO-based controllers of the 
UPFC -POD and PSS, the power system provides superior performance in comparison with their individual controllers in term of reducing the settling time, overshoot, low-frequency oscillations and improve system stability.

\section{REFERENCES}

Ajami, A. and R. Gholizadeh, 2012. Optimal design of UPFC-based damping controller using imperialist competitive algorithm. Turk. J. Electr. Eng. Comput. Sci., 20: 1109-1122.

Alomoush, M., 2017. Concurrent optimal design of TCSC and PSS using symbiotic organisms search algorithm. Turk. J. Electr. Eng. Comput. Sci., 25: 3904-3919.

Esmaili, M.R., R.A. Hooshmand, M. Parastegari, P.G. Panah and S. Azizkhani, 2013. New coordinated design of SVC and PSS for multi-machine power system using BF-PSO algorithm. Procedia Technol., 11: 65-74.

Heydari, H.R., H.S.A.B. Mahani, R. Dahim and M. Mohammadinejad, 2014. Coordinated designing between PSS and SVC POD controller using DE algorithm. Intl. J. Tech. Phisical Prob. Eng., 6: 22-28.

Hussain, A.N., F. Malek, M.A. Rashid and M.H.A. Malek, 2013a. Performance improvement of power system stability by using multiple damping controllers based on PSS and the UPFC. Intl. J. Eng. Technol., 5: 3257-3269.

Hussain, A.N., F. Malek, M.A. Rashid, L. Mohamed and N.A. Mohd Affendi, 2013b. Optimal coordinated design of multiple damping controllers based on PSS and UPFC device to improve dynamic stability in the power system. Math. Probl. Eng., 2013: 1-16.

Kaveh, A. and N. Farhoudi, 2013. A new optimization method: Dolphin echolocation. Adv. Eng. Software, 59: 53-70.

Kaveh, A. and N. Farhoudi, 2016. Dolphin echolocation optimization: Continuous search space. Adv. Comput. Des., 1: 175-194.
Kaveh, A., L. Jafari and N. Farhoudi, 2015. Truss optimization with natural frequency constraints using a dolphin echolocation algorithm. Asian J. Civ. Eng., 16: 29-46.

Khadanga, R.K. and J.K. Satapathy, 2015. Coordinated design of PSS and SSSC based damping controller using evolutionary algorithms. Proceedings of the Annual IEEE India Conference on INDICON, December 17-20, 2015, IEEE, New Delhi, India, pp: 1-6.

Mustafa, M.W., J. Usman, N.A. Arzeha and N.S. Ab Khalid, 2013. Application of PSS and facts devices for damping low frequency oscillations in power systems. A. Arch. Des Sci., 66: 254-264.

Prasertwong, K., N. Mithulananthan and D. Thakur, 2010. Understanding low-frequency oscillation in power systems. Intl. J. Electr. Eng. Educ., 47: 248-262.

Safari, A., H. Shayeghi and S. Jalilzadeh, 2015. Robust coordinated design of upfe damping controller and PSS using chaotic optimization algorithm. J. Iran. Assoc. Electr. Electron. Eng., 12: 55-62.

Sedighizadeh, M., M. Sarvi, B. Minooie and M. Akbari, 2013. Power system stability enhancement using a NSPSO designed UPFC damping controller. Intl. Sci. Press India, 5: 125-141.

Shegaw, M.A. and T.R. Jyothsna, 2017. Design and analysis of power system stabilizer and unified power flow controller for enhancements of transient stability. Intl. Res. J. Eng. Technol., 4: 354-364.

Surjan, B.S. and R. Garg, 2012. Power system stabilizer controller design for SMMB stability study. Intl. J. Eng. Adv. Technol., 2: 209-214.

Usman, J., M.W. Mustafa and G. Aliyu, 2012. Design of AVR and PSS for power system stability based on iteration particle swarm optimization. Intl. J. Eng. Innovative Technol., 2: 307-314. 